\title{
FORMAÇÃO E TRABALHO DOCENTE: intencionalidades da BNC-Formação Continuada
}

\author{
Eliane Miranda Costa \\ Universidade Federal do Pará - UFPA, Brasil \\ Cleide Carvalho de Matos \\ Universidade Federal do Pará - UFPA, Brasil \\ Vivianne Nunes da Silva Caetano \\ Universidade Federal do Pará - UFPA, Brasil
}

\begin{abstract}
Resumo
O texto apresenta a análise sobre a política pública de formação continuada de professores e tem como perspectiva provocar reflexões acerca da intencionalidade da Resolução CNE/CP $\mathrm{n}^{\circ} 1$, de 27 de outubro de 2020, especificamente da BNC-Formação Continuada e da implicação da mesma para o trabalho docente e o processo formativo do/a aluno/a da educação básica. Trata-se de um texto de caráter bibliográfico e documental que procurou responder aos seguintes questionamentos: Como a Formação Continuada é pautada pela Resolução CNE/CP $\mathrm{n}^{\circ}$ 1/2020 e qual a intencionalidade da BNC-Formação Continuada? Qual a implicação dessa Resolução e Base para o trabalho docente e o processo formativo do aluno da educação básica? Destaca-se que as políticas da Educação Básica ao Ensino Superior no Brasil, implementadas, a partir de 1990 e reestruturadas no contexto atual alinham-se ao pensamento neoliberal. Nossa reflexão sobre política de formação continuada de professores se insere no contexto de reestruturação produtiva pela qual o sistema capitalista neoliberal tem produzido novos arranjos no mercado de trabalho, os quais afetam diretamente a educação, os professores e sua formação inicial e continuada para adequar o trabalhador aos ditames do capital.
\end{abstract}

Palavras-chave: Formação; Trabalho docente; BNC-Formação Continuada.

\begin{abstract}
The paper presents the analysis of the public policy for continued teacher training under the perspective of stimulating reflection on the intents of Resolution CNE/CP $n^{\circ} 1$, namely BNCContinued Training and the consequences it brings to teaching and the formative process of students in basic education. It is a text of bibliographic and documental nature which has sought to respond to the following questions: How Continued Training is addressed by Resolution CNE/CP ${ }^{\circ} 1$ and which are the intents of BNC-Continued Training? What are the consequences of such Resolution and National Curricular Base for teaching and the formative process of students in basic education? Highlight is that Brazilian educational policies, implemented from 1990 on and re-structured in the present context, are aligned with the neoliberal thinking. Our reflection on the policy for continued teacher training lies in the context of productive re-structuring through which the capitalist system has been producing new arrangements in the labor market that directly affect education, teachers and their basic and ongoing training in order to match workers with the dictates of capital.
\end{abstract}

Keywords: Formation; Teacher Work; BNC-Continued Training. 


\section{Introdução}

Não há dúvidas de que a formação docente (inicial e continuada) é estratégia e ferramenta fulcral no desenvolvimento da escolarização e edificação da qualidade do ensino na escola básica (Magalhaes; Azevedo, 2015; Amador, 2019; Evangelista, 2021). De acordo com Soares (2018, p. 57), "a educação e o professor [são] elementos fundamentais para o desenvolvimento nacional e o estabelecimento da ordem econômica mundial". Isso justifica o interesse e a interferência do grande capital e dos reformadores empresariais (Freitas, 2012), ou melhor, dos "Aparelhos privados de hegemonia burguesa", como denomina Evangelista (2021), nas políticas para a educação brasileira, sobretudo a partir de 1990.

$\mathrm{Na}$ lógica desses aparelhos e do capitalismo a formação de professores e tudo que diz respeito à escola e educação pública de modo geral pode ser transformado em mercadoria e negócio rentável. Ideário que vem ganhando fôlego e expressividade com a inserção do pensamento neoliberal na educação brasileira, a partir da agenda de reformas estabelecidas nos anos de 1990 e intensificadas nas atuais reformas educacionais em todos os níveis da Educação Básica ao Ensino Superior. Em outras palavras, podemos dizer que por meio das reformas educacionais o capital neoliberal tem imprimido ao Estado brasileiro sua ideologia burguesa, fato que explica o alinhamento da política educacional brasileira aos preceitos do capitalismo, com a aprovação de dispositivos de controle e regulação.

O mais recente dispositivo é a Resolução CNE/CP $n^{\circ} 1 / 2020$, que dispõe sobre as Diretrizes Curriculares Nacionais para a Formação Continuada de Professores da Educação Básica e institui a Base Nacional Comum para a Formação Continuada de Professores da Educação Básica (BNC-Formação Continuada). Esse documento integra o pacote de dispositivos aprovados com o intuito de materializar a Base Nacional Comum Curricular da Educação Básica (BNCC) referente às etapas da Educação Infantil e Ensino Fundamental (Resolução CNE/CP no 2/2017) e o Ensino Médio (Resolução CNE/CP no 04/2018). A BNCC é o eixo e a principal escala estruturante de um projeto societal, que ancorada no capital neoliberal e suas faces meritocrática, excludente e neofacista, tem por perspectiva a padronização, homogeneização e elitização da educação pública brasileira.

Neste texto, a perspectiva é provocar reflexões acerca da intencionalidade da Resolução CNE/CP $n^{0}$ 1, especificamente da BNC-Formação Continuada e da implicação da mesma para o trabalho docente e processo formativo do aluno da educação básica. Para promover tal debate elencamos os seguintes questionamentos: Como a formação continuada é pautada pela Resolução CNE/CP n ${ }^{\circ}$ 1/2020 e qual a intencionalidade da BNC-Formação Continuada? Qual a implicação dessa Resolução e base para o trabalho docente e o processo formativo do aluno da educação básica?

A fonte que sustenta nossa discussão é composta por uma base bibliográfica e uma base documental. No âmbito da bibliográfica, formada por produções submetidas a um tratamento analítico (Gil, 2009), contamos com artigos e livros de teóricos que têm a formação docente como foco de estudo. Entre os autores que recorremos, destacam-se: Freire (1996); Freitas (2012; 2020); Curado Silva (2017; 2020), Evangelista (2021); Saraiva Souza (2020), entre outros. A base documental é formada, prioritariamente, pela Resolução CNE/CP n ${ }^{\circ}$ 1/2020 e 
seu anexo, a BNC-Formação Continuada. A análise e interpretação dessas fontes amparamse em uma abordagem crítica e reflexiva do objeto de estudo, considerando o debate atual acerca da política de formação docente no Brasil. Mas também contamos com estudos que tratam da reforma do aparelho do Estado brasileiro no contexto dos anos de 1990 - cujo marco central é a Lei de Diretrizes e Bases da Educação Nacional (LDBEN) no 9.394/1996 -, os quais nos indicam importantes indícios, fissuras e fragmentos para compreendermos a situação atual da formação continuada.

Estruturamos esta discussão em dois tópicos, além desta Introdução. Iniciamos com a uma abordagem sobre a política de formação docente do Estado brasileiro, evidenciando suas respectivas concepções e modelos. Posteriormente analisamos a Formação Continuada de Professores no contexto da Resolução CNE/CP n n $^{\circ}$ 1/2020 e seu anexo BNC-Formação Continuada, destacando a influência do pensamento neoliberal na configuração de uma política que tem por finalidade materializar a BNCC. Ao finalizar, destacamos ser a presente política estratégia de padronização do trabalho docente.

\section{Políticas de formação docente do Estado brasileiro: concepções e modelos}

Falar em políticas públicas voltadas à educação, saúde, Previdência, habitação etc., no contesto histórico que estamos vivendo, é um desafio, dado os constantes ataques e retrocessos que essas políticas vêm sofrendo nos últimos anos, sobretudo no atual governo, cujas ações têm materializado o projeto de poder de grupos conservadores e neopentecostais que conduziram o atual presidente ao poder.

Neste artigo, pautamos a política pública de formação continuada de professores. Compreende-se as políticas públicas como responsabilidade do Estado no que diz respeito à "[...] implementação e manutenção a partir de um processo de tomada de decisões que envolve órgãos públicos e diferentes organismos e agentes da sociedade relacionados à política implementada" (Höfling, 2001, p. 31). A educação é uma política pública "[...] de responsabilidade do Estado - mas não pensada somente por seus organismos". (Höfling, 2001, p. 31).

Nossa reflexão sobre política de formação continuada de professores se insere no contexto de reestruturação produtiva pela qual o sistema capitalista tem produzido novos arranjos no mercado de trabalho que afetam diretamente a educação, os professores e sua formação inicial e continuada para adequar o trabalhador aos ditames do capital.

Consequentemente, repensar a formação de professores constitui-se parte fundamental deste processo, uma vez que estes possibilitam a reestruturação produtiva ao formar os novos trabalhadores. Surge, então, a necessidade de se reformular os cursos de formação de professores para que estes deem conta desta tarefa e, assim, o debate sobre um novo paradigma de conhecimento e novos 
modelos de formação ganha destaque nas políticas, propostas e nos projetos. (Curado Silva, 2017, p. 131).

A formação inicial e continuada de professores ganhou notoriedade sobretudo a partir da promulgação da Lei de Diretrizes e Bases da Educação (LDB), Lei n 9.394/1996. Por meio deste documento o Estado brasileiro estabeleceu as bases para a educação pública e para a formação de professores.

Na LDB a Formação Continuada, doravante FC, é objeto do Art. 62, que trata da formação docente para atuar na Educação Básica. O tema é abordado nos parágrafos $1^{\circ}$ e $2^{\circ}$ do referido artigo.

$\S 1^{\circ}$ A União, o Distrito Federal, os Estados e os Municípios, em regime de colaboração, deverão promover a formação inicial, a continuada e a capacitação dos profissionais de magistério. (Incluído pela Lei $\mathrm{n}^{\circ} 12.056$, de 2009).

$\S 2^{\circ}$ A formação continuada e a capacitação dos profissionais de magistério poderão utilizar recursos e tecnologias de educação a distância. (Incluído pela Lei

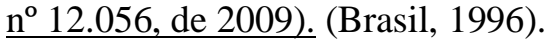

A referência à formação continuada na atual LDB foi acrescentada apenas em 2009 pela Lei $\mathrm{n}^{\circ}$ 12.056. Os incisos fazem menção à formação continuada e a capacitação dos docentes as quais devem ser promovidas pela União, o Distrito Federal, os Estados e os Municípios por meio de recursos tecnológicos e educação a distância. Anteriormente, a única referência ao tema era no art. 87, parágrafo $3^{\circ}$, inciso III - "realizar programas de capacitação para todos os professores em exercício, utilizando também, para isto, os recursos da educação a distância” (Brasil, 2009, grifo nosso); observa-se que na lei utilizou-se a palavra capacitação, e somente posteriormente houve acréscimo do termo formação continuada.

O Plano Nacional de Educação (PNE), Lei n ${ }^{\circ}$ 13.005/2014, traz o tema da formação continuada na meta 16 , a saber:

Formar, em nível de pós-graduação, 50\% (cinquenta por cento) dos professores da educação básica, até o último ano de vigência deste PNE, e garantir a todos(as) os(as) profissionais da educação básica formação continuada em sua área de atuação, considerando as necessidades, demandas e contextualizações dos sistemas de ensino. (Brasil, 2014).

A formação continuada dos professores da Educação Básica é pensada no PNE em dois aspectos; primeiro, em nível de pós-graduação, como um processo contínuo incentivado por meio da oferta de bolsas de estudo para os que pretendem ingressar na pós-graduação; por outro lado, em um segundo aspecto, propõe-se ampliar o programa de acervo de obras didáticas, paradidáticas e de obras literárias. Tais ações são estruturadas pelo regime de colaboração entre os Estados, o Distrito Federal e os Municípios, que deverão fazer um diagnóstico sobre a demanda de formação continuada e a oferta por parte de instituições públicas de ensino superior. 
O PNE propõe também a definição de diretrizes nacionais para fortalecer a política nacional de formação de professores e professoras da Educação Básica. Fato ocorrido em 2015 com a aprovação da Resolução CNE/CP $n^{\circ} 2$, de $1^{\circ}$ de julho de 2015, que definiu as Diretrizes Curriculares Nacionais (DCN) para a formação inicial em nível superior (cursos de licenciatura, cursos de formação pedagógica para graduados e cursos de segunda licenciatura) e para a FC. Nessa Resolução, a formação continuada é pensada de forma articulada com a formação inicial, a qual deve ocorrer por meio de "[...] cursos programas e ações para além da formação mínima exigida ao exercício do magistério na educação básica, tendo como principal finalidade a reflexão sobre a prática educacional e a busca de aperfeiçoamento técnico, pedagógico, ético e político [...] (Brasil, 2015, art. 16).

Do mesmo modo que o PNE, a Resolução CNE/CP $\mathrm{n}^{\circ}$ 2/2015 também concebe a formação continuada como progressão de estudos no âmbito da pós-graduação latu sensu $e$ stricto sensu, conforme estabelece o Art. 17

A formação continuada, na forma do artigo 16, deve se dar pela oferta de atividades formativas e cursos de atualização, extensão, aperfeiçoamento, especialização, mestrado e doutorado que agreguem novos saberes e práticas, articulados às políticas e gestão da educação, à área de atuação do profissional e às instituições de educação básica, em suas diferentes etapas e modalidades da educação. (Brasil, 2015).

Em 2016, foi promulgado o Decreto $n^{0} 8.752$, que regulamentou a Política Nacional de Formação dos Profissionais da Educação Básica, cuja finalidade é fixar princípios e objetivos gerais para orientar a formação inicial e continuada de professores por meio da organização de programas e ações em regime de colaboração entre os sistemas de ensino, o Ministério da Educação (MEC), os Estados, o Distrito Federal e os Municípios, em consonância com o PNE (Art. 3, inciso I).

O referido decreto estabelece, no artigo 2, os princípios gerais para a formação inicial e continuada dos profissionais da educação com o propósito de atender as especificidades do trabalho docente e as necessidades das etapas e modalidades da educação básica. Tais como:

I - o compromisso com um projeto social, político e ético que contribua para a consolidação de uma nação soberana, democrática, justa, inclusiva e que promova a emancipação dos indivíduos e dos grupos sociais;

V - a articulação entre teoria e prática no processo de formação, fundada no domínio de conhecimentos científicos, pedagógicos e técnicos específicos, segundo a natureza da função;

VI - a articulação entre formação inicial e formação continuada, e entre os níveis, as etapas e as modalidades de ensino;

VII - a formação inicial e continuada, entendidas como componentes essenciais à profissionalização, integrando-se ao cotidiano da instituição educativa e considerando os diferentes saberes e a experiência profissionais;

VIII - a compreensão dos profissionais da educação como agentes fundamentais do processo educativo e, como tal, da necessidade de seu acesso permanente a 
processos formativos, informações, vivência e atualização profissional, visando à melhoria da qualidade da educação básica e à qualificação do ambiente escolar. (Brasil, 2016).

A formação inicial e continuada são "[...] entendidas como componentes essenciais a profissionalização" (Brasil, 2016, Art. 2, inciso VII). Ou seja, a formação é condição para o ingresso no magistério e para a desenvolvimento dos saberes da docência. De acordo com Tardiff (2002), a profissão docente mobiliza um conjunto de saberes que se articulam, quais sejam, saberes profissionais ou pedagógicos, saberes disciplinares, saberes curriculares e saberes experienciais. Os saberes pedagógicos, disciplinares e curriculares são apresentados aos professores nos cursos de formação inicial; e os saberes experienciais, por sua vez, são oriundos das experiências dos docentes, vivenciadas no exercício da profissão.

O referido Decreto propõe a formação inicial e continuada de professores pautada em princípios e valores democráticos, na defesa dos direitos humanos e no respeito ao meio ambiente, nas diferenças e na diversidade sociocultural (étnica, gênero, religiosa, geracional, etc.). Essa concepção de formação exige o desenvolvimento de ações articuladas entre os entes federados e as instituições de ensino superior, de modo a promover uma educação que objetive contribuir para o exercício de uma efetiva cidadania.

Após o golpe jurídico parlamentar que resultou na ascensão do governo Temer (31 ago. 2016-2018), e posteriormente na eleição de Bolsonaro (2019), as políticas educacionais que vinham sendo construídas para a formação continuada de professores foram interrompidas e/ou substituídas. Grupos empresariais ligados ao Todos pela Educação e ao Movimento Pela Base assumiram forte influência no MEC, principalmente no Conselho Nacional de Educação (CNE), que além postergarem a implementação da Resolução CNE/CP2/2015, rapidamente elaboraram uma nova Resolução, que não mantém nenhuma relação com a Resolução anterior, agilizaram a novas versões da BNCC e da BNC-Formação, com a flexibilização da formação de acordo com interesses do capital (Albino; Silva, 2019).

Nesse processo de reformulação da política de formação continuada de professores é importante situarmos outras instituições que têm contribuído para o desenvolvimento de experiências educacionais de outros contextos para a realidade brasileira. Tais instituiçõos desempenharam papel importante na definição da política educacional, contribuindo para que as modificações realizadas na legislação atendessem as exigências do capital. Em outras palavras, as alterações na formação continuada e no currículo da educação básica avançaram em função das orientações dessas instituições.

Neste estudo, destacamos o papel da OCDE (Organização para a Cooperação e Desenvolvimento Econômico) e da UNESCO (Organização das Nações Unidas para a Educação, a Ciência e a Cultura) no processo de reformulação da formação continuada de professores. Essas instituições consideraram que o problema da educação está na forma como os professores ensinam; então, para haver mudanças significativas nos indicadores educacionais, é fundamental repensar os modelos de formação desenvolvidos, seja na formação inicial chamada de "formação pré-serviço", seja na formação continuada. "Emerge, portanto, a noção de educação e formação ao longo de toda vida, [...]”. (Saraiva; Souza, 2020, 
p. 142). Deste modo, “[...] os professores precisam renovar permanentemente os seus conhecimentos, sob o risco de se tornarem obsoletos. Daí a ênfase na capacidade do professor de formar o aluno para o século XXI" (Saraiva; Souza, 2020, p. 142). Esse processo de formação é denominado pelos Organismos Internacionais como "Desenvolvimento Profissional Docente" (Saraiva; Souza, 2020).

De acordo com Saraiva e Souza (2020, p. 134), a OCDE estruturou o setor educacional em cinco áreas de trabalho, destas, destacamos uma área que está diretamente relacionada com a formação de professores, a saber: "[...] Ensino e Aprendizagem, com a premissa de que o modo como os professores ensinam e os alunos aprendem são questões centrais no desenvolvimento de políticas educacionais". À vista disso, para promover as transformações consideradas necessárias no processo de ensino-aprendizagem é necessário repensar a formação continuada de professores. Tais transformações devem ser promovidas por meio de políticas educacionais alinhadas às orientações dos Organismos Internacionais, como a OCDE.

Por sua vez, a UNESCO, segundo Saraiva e Souza (2020), atua na América Latina e Caribe por meio da Oficina para a Educação da América Latina e Caribe (Orealc), cuja intenção é assegurar o alinhamento da formação docente às orientações da referida organização, a qual considera que:

A falta e/ou a inadequação de apoio e desenvolvimento profissional contínuo de professores e padrões nacionais para a profissão docente são fatores-chave que contribuem para a baixa qualidade dos resultados de aprendizagem. Sistemas educacionais bem-sucedidos, que garantem a qualidade $\mathrm{e}$ a equidade, concentraram-se em contínuo desenvolvimento profissional que apoia a aprendizagem e o aperfeiçoamento dos próprios professores ao longo de suas carreiras. (UNESCO, 2016, p. 54 apud Saraiva; Souza, 2020, p. 138).

Para a UNESCO, a falta e/ou inadequação na formação continuada de professores reverbera na baixa qualidade da educação. Daí a necessidade de estabelecer padrões nacionais para orientar a formação continuada, bem como incentivar o aperfeiçoamento dos professores ao longo da carreira. A Orealc, por meio do Projeto Estratégico Regional sobre Docentes para a América Latina, vem promovendo, desde 2011, ações para o fortalecimento da profissão docente. "Esse projeto buscou discutir quatro grandes dimensões: formação inicial; formação continuada e desenvolvimento profissional; carreira docente; e instituições e processos de políticas docentes". (Saraiva; Souza, 2020, p. 138).

Deste modo, a formação docente na perspectiva da formação humana é "[...] substituída pela construção de capacidades cognitivas flexíveis e competências relacionadas ao saber fazer" (Curado Silva, 2017, p. 122); pois considera-se que essas competências “[...] permitem ao trabalhador resolver rapidamente os problemas da prática cotidiana e adaptar-se a um universo produtivo que muda rápida e constantemente". (Curado Silva, 2017, p. 122).

Nesse sentido, as reformas dos cursos de licenciaturas engendradas no contexto da reestruturação produtiva [...] evidenciam uma alteração epistemológica na concepção de 
formação de professores, com maior evidência para a prática (Curado Silva, 2017, p. 123). Por meio de tais políticas houve a redefinição da formação continuada dos docentes e uma cisão entre formação inicial e continuada.

Assim, a formação na/para a prática tem sido a perspectiva dominante nas novas políticas de formação, que ecoaram, evidentemente, nas reformas curriculares. A qualificação docente é preconizada como um exercício prático, que deve ser baseado na experiência, na atividade prática, o que, aparentemente, é considerado o eixo da formação docente. (Curado Silva, 2017, p. 123).

As reformas promovidas nos cursos de formação de professores não estão desvinculadas das amplas reformas educacionais em curso. A implementação da BNCC, a Reforma do Ensino Médio, por exemplo, trazem novas demandas para a formação e para a docência, tornando-se o núcleo central tanto da formação inicial quanto continuada. Por isso, o futuro docente, desde o início do curso, deverá entrar em contato com a escola para desenvolver as competências e habilidades consideradas necessárias para resolver os problemas práticos em sala de aula.

Para Pereira e Evangelista (2019, p. 69, grifo do original), a "Formação e trabalho docentes tornaram-se mais complexos ao longo do período, posto que a burguesia, após a reestruturação produtiva e suas espúrias decorrências, lançou sobre os professores slogans que atribuíam à sua incapacidade o aumento do desemprego". Essa associação entre educação e emprego gera questionamentos sobre a importância da escola para a formação do trabalhador e sobre o papel do professor neste processo. Deste modo, há uma inversão de responsabilidade, dado que o sistema capitalista, por meio de seus organismos, culpam a escola e os professores pelo aumento do desemprego, enquanto os processos de exclusão social intensificados no processo de reestruturação produtiva do capital não são questionados.

Para atender tais questionamentos, associou-se à política de formação de professores as avaliações em larga escala, que exigem dos sistemas de ensino responsabilidades com o desenvolvimento de uma educação com foco na preparação dos discente para realizarem exames, "[...] o que engessa o trabalho escolar a formas de medição do desempenho com políticas de punição ou de premiação". (Hypolito, 2021, p. 5). Essas avaliações têm implicações diretas nas políticas educacionais.

Um dos efeitos da mobilidade dessas políticas é a produção local de políticas, como se fossem originais. A BNCC é a expressão local de uma padronização curricular global, o que se poderia chamar de Currículo Nacional para recuperarmos um pouco uma expressão usada nos anos de 1990 e que parece ter sido evitada recentemente para dar outro significado ao debate ou confundir expressões históricas (Hypolito, 2021, p. 5).

A BNCC representa a materialização da influência dos Organismos Internacionais na política educacional, que por meio de consultorias e relatórios orientam os países a tornarem 
seus sistemas mais eficientes. Uma das principais estratégias consideradas efetivas para a realização desta finalidade é a padronização curricular, ou seja, a BNCC

[...] está baseada em um modelo de padronização curricular, baseado em competências, supostamente desenvolvido para melhorar a preparação e o desempenho estudantil para os exames padronizados e para as atividades avaliativas de cada sistema para fins de melhoria do IDEB. (Hypolito, 2021, p. 7).

No entanto, apesar de todo investimento em propaganda para criar consensos sobre as melhorias que a BNCC traria ao ensino no Brasil, como por exemplo, nos indicadores do IDEB (Índice de Desenvolvimento da Educação Básica), “[...] os resultados no PISA não indicam o mesmo sucesso, o que nos mostra que todo o esforço do GERM [Movimento de Reforma Educacional Global] e da padronização não tem surtido o efeito esperado para o sucesso escolar" (Hypolito, 2021, p. 7).

A ideia de "padronização curricular" materializada na Educação Básica por meio da BNCC repercute diretamente na formação de professores. O objetivo é articular a formação docente aos preceitos da BNCC. Deste modo, a formação de professores passa a ser orientada pela concepção de educação presente nas políticas implementadas na Educação Básica. "Por mais que tentemos vislumbrar um meio de buscar alternativas curriculares, tudo indica que o cerco está cada vez mais definido. Principalmente, para a Formação de Professores" (Hypolito, 2021, p. 7).

\section{A formação continuada de professores no contexto da Resolução CNE/CP no 1/2020 e seu anexo BNC-Formação Continuada: intencionalidade e implicação para o trabalho docente}

Aprovada em 27 de outubro de 2020, a Resolução CNE/CP n 1/2020 dispõe sobre as Diretrizes Curriculares Nacionais para a Formação Continuada de Professores da Educação Básica e institui a Base Nacional Comum para a Formação Continuada de Professores da Educação Básica (BNC-Formação Continuada), tendo por referência a implantação da BNCC (Art. 2). Desse modo, a BNC-FC tem por prerrogativa abranger as competências profissionais estabelecidas pela $\mathrm{BNCC}$, o que inclui 10 competências gerais docentes e competências específicas vinculadas às dimensões do conhecimento, da prática e do engajamento e suas respectivas áreas, a saber: Área do Conhecimento e do Conteúdo Curricular; Área Didática-Pedagógica; Área de Ensino e Aprendizagem para Todos os Alunos; Área sobre o Ambiente Institucional e o Contexto Sociocultural; e Área sobre o Desenvolvimento e Responsabilidades Profissionais (Brasil, 2020).

De acordo com o Art. $3^{\circ}$ dessa Resolução, a formação continuada, assim como a inicial, abrange três dimensões: I- conhecimento profissional, II- prática profissional; e III engajamento profissional, que devem ser desenvolvidas de forma interdependente. A BNCFormação Continuada define que o conhecimento profissional refere-se à aquisição pelo 
professor de conhecimentos específicos da área de atuação, do ambiente institucional e cultural e do autoconhecimento. Assim, dominar, conhecer e auto-conhecer-se são os verbos que definem e orientam, nas áreas, anteriormente citadas, a ação docente.

A prática profissional, dividida em prática profissional pedagógica e prática profissional institucional, orienta-se pelos verbos: planejar, incentivar, viabilizar, apoiar, utilizar, contribuir e instituir, para estabelecer as competências específicas nas citadas áreas. A prática profissional pedagógica refere-se aos aspectos didáticos e pedagógicos, e a prática profissional institucional trata da cultura organizacional das instituições do ensino e do contexto sociocultural. Na dimensão engajamento profissional, acentuam-se o compromisso do professor com suas atribuições e responsabilidades docentes. Desse modo, fortalecer, demonstrar, interagir, atuar e investir constituem-se eixos específicos da ação docente (Brasil, 2020).

Em nossa leitura, trata-se de uma política para padronizar a formação à revelia de competências previamente determinadas que reduz o professor a "executor de tarefas", ou melhor, a "um educador com muito pouco de formador, com muito mais de treinador, de transferidor de saberes, de exercitador de destrezas" (Freire, 1996, p. 73), e cumpridor de metas. Impõe-se, na verdade, uma formação de base tecnicista, em que prevalece como ideia a figura de "um profissional que deve ser responsável, engajado com seu desenvolvimento, mas num aspecto de formação do indivíduo isolado, que aprende com suas experiências" (Saraiva; Souza, 2020, p. 66). Desse modo, tem-se um profissional muito mais comprometido com a adequação social do capital que com as transformações sociais.

Compartilhamos do entendimento de que há

[...] em jogo não apenas a modificação política dos processos educacionais - que praticam e agravam o apartheid social -, mas a reprodução da estrutura de valores que contribui para perpetuar uma concepção de mundo baseada na sociedade mercantil (Jinkings, 2005, p. 12, grifo do original).

Diante de tal perspectiva, o professor é transformado em peça-chave, e sua formação em elemento estratégico para consolidar a mencionada sociedade.

$\mathrm{Na}$ letra da Resolução a FC é interpretada como "componente essencial da profissionalização docente (Brasil, 2020, Art. $4^{\circ}$ ), o que denota o reconhecimento da importância e necessidade dessa modalidade formativa. É consenso que a FC é indispensável para o desenvolvimento da prática educativa, pois possibilita ao professor contextualizar de forma crítica e reflexiva a produção e transmissão do conhecimento. Essa etapa formativa é um potencial espaço de diálogo crítico com a prática.

Para Freire $(1996,21)$, na formação permanente “[...] o momento fundamental é o da reflexão crítica sobre a prática. É pensando criticamente a prática de ontem que se pode melhorar a próxima prática". Mas, pensar criticamente a prática exige uma base teórica sólida, pois a teoria dá sustentação à prática e esta, à teoria. Queremos dizer com isso que não se constrói uma prática educativa sem fundamentação teórica (explicita ou não), pois embora de naturezas distintas, teoria e prática são indissociáveis, e na "docência acontecem 
numa relação dialética, isto é, as ações de ensinar não estão isentas do pensamento teórico e é, ele que demarca a intencionalidade da atividade prática" (ANPED, 2019, on-line). Escassear ao professor

a teoria e o conhecimento próprio a seu ofício de sua formação e de seu trabalho, corre-se o risco de suprimir também a possibilidade do acesso dos trabalhadores ao conhecimento histórico e socialmente produzido e sistematizado (Soares, 2018, p. 82).

Na Resolução em estudo identifica-se aqui que não se leva em conta a relação dialética entre teoria e prática. A tendência é uma formação continuada de caráter pragmático, isto é, que reduz os processos formativos a transmissão de conteúdos relacionados ao desenvolvimento de competências e habilidades pautadas no saber fazer. Aspectos que se verifica nos princípios que norteiam o modelo formativo desenhado pela presente Resolução $\left(\right.$ Art. $\left.5^{\circ}\right)$. Entre os princípios, destacamos,

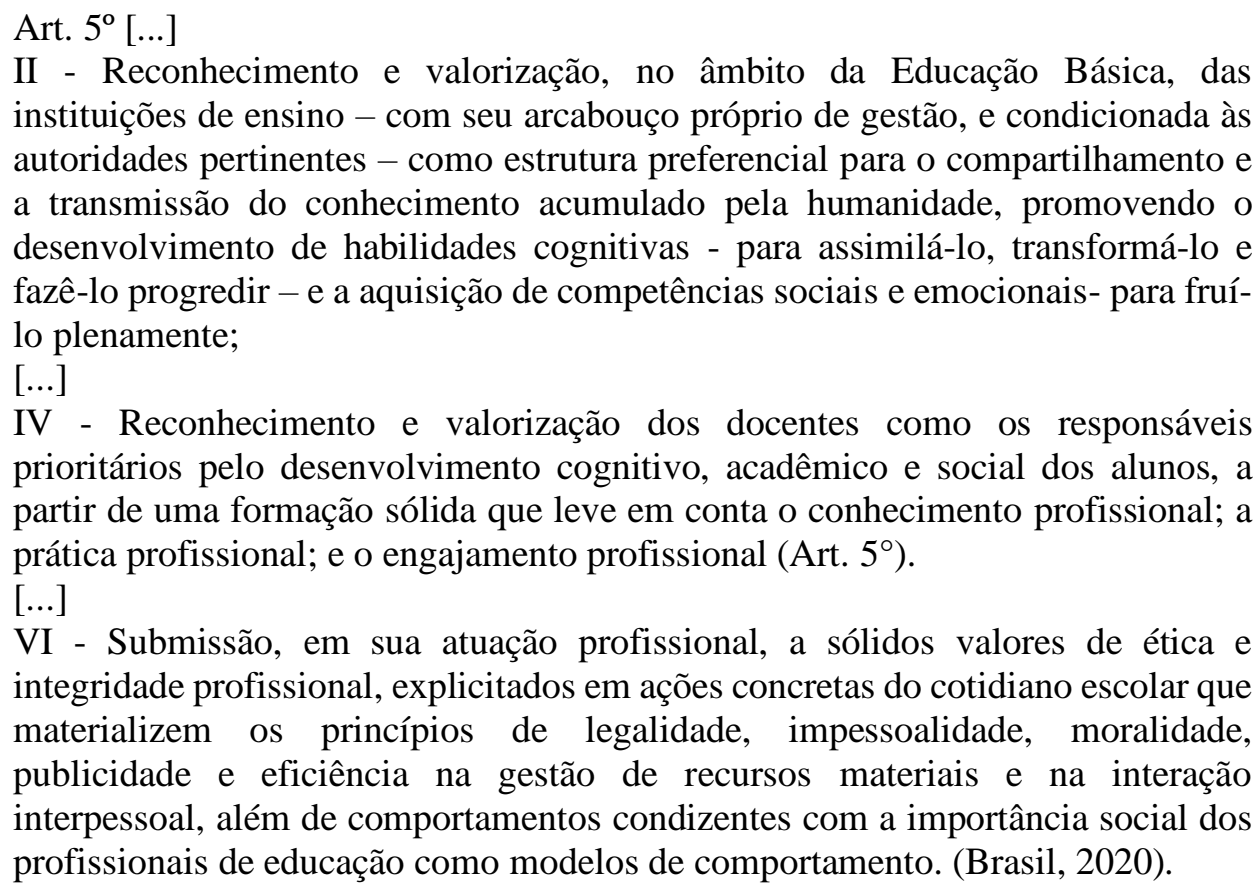
integridade profissional, explicitados em ações concretas do cotidiano escolar que materializem os princípios de legalidade, impessoalidade, moralidade, publicidade e eficiência na gestão de recursos materiais e na interação interpessoal, além de comportamentos condizentes com a importância social dos profissionais de educação como modelos de comportamento. (Brasil, 2020).

Estes princípios nos indicam que o professor preterido deve ser um potencial acompanhador das aprendizagens essenciais para a inserção do aluno no mercado de trabalho. Em outras palavras, o professor torna-se

[...] um instrumento de transmissão do conteúdo, [ou seja], assume a tarefa de desenvolver no discente a capacidade para aprender continuamente; trabalhar em equipe, ser flexível e cooperativo; saber solucionar problemas; dinâmicas que 
também cabe a ele, no processo de aprender a aprender, elementos que compõe as competências (Curado Silva, 2020, p. 108).

Verifica-se que entre tais competências figura a competência sócio-emocional como elemento central do trabalho docente, o que reforça a performance meritocrática. Alarga essa dinâmica questões como criatividade, autonomia, eficiência, enquanto indispensável da qualidade formativa. Podemos dizer que a qualidade formativa do/a professor/a fundamentase no eficientismo, o que sugere reduzir o direito à educação a concessão de serviços educacionais, tendo por referência uma dimensão prático-instrutiva que vincula a qualidade da educação a resultados de avaliações externas e internas. Daí analisar a política de FC em curso no país, subordinada ao pragmatismo e neotecnicismo que procuram se efetivar mediante processos educativos que reforçam os interesses da elite dominante e do sistema produtivo.

Nessa seara, verifica-se que o protótipo de “[...] professor empreendedor de si mesmo é o docente desejado e capaz de formar pessoas para o século XXI" (Saraiva; Souza, 2020, p. 143). Este profissional, enredado pela falsa liberdade e autonomia, não desenvolverá qualquer percepção estrutural da sua condição de subordinado e da educação como mercadoria, fato que faz do/a professor/a personagem ideal para materializar os preceitos do paradigma neoliberal.

No Art. $6^{\circ}$ da Resolução em estudo aqui, que trata dos fundamentos pedagógicos da FC de docentes da Educação Básica, o caráter pragmático encontra ressonância na ideia de desenvolvimento permanente. Embora o foco na permanência seja positivo, visto reconhecer a incompletude humana da qual fala Freire (1996) e mediante a isso reforça a necessidade da formação contínua, a ênfase no desenvolvimento ressoa problemático. Isso porque indica como tendência um processo formativo enquanto demanda exclusiva do capital. Em outros termos, o desenvolvimento permanente traduz-se em ingrediente da receita neoliberal para atender os serviços e direitos mercadológicos.

O Art. $7^{\circ}$, por sua vez, aborda as características da FC, que são: "foco no conhecimento pedagógico do conteúdo; uso de metodologias ativas de aprendizagem; trabalho colaborativo entre pares; duração prolongada da formação e coerência sistêmica." (Brasil, 2020). Como se observa nesse artigo, reduz-se a educação ao desenvolvimento e a aprendizagem, pressupondo que as questões de ensino tornam-se determinante como "disputas entre métodos de ensinar" (Barreto, 2010, p. 429).

Art. $7^{\circ}$ - A Formação Continuada, para que tenha impacto positivo quanto à sua eficácia na melhoria da prática docente, deve atender as características de: foco no conhecimento pedagógico do conteúdo; uso de metodologias ativas de aprendizagem; trabalho colaborativo entre pares; duração prolongada da formação e coerência sistêmica:

I - Foco no conhecimento pedagógico do conteúdo - pressupõe o desenvolvimento de conhecimentos de como os estudantes aprendem, no uso de estratégias diferentes para garantir o aprendizado de todos e na ampliação do repertório do 
professor que lhe permita compreender o processo de aprendizagem dos conteúdos pelos estudantes;

II - Uso de metodologias ativas de aprendizagem - as formações efetivas consideram o formador como facilitador do processo de construção de aprendizados que ocorre entre e/ou com os próprios participantes, sendo que entre as diferentes atividades de uso de metodologias ativas estão: a pesquisa-ação, o processo de construção de materiais para as aulas, o uso de artefatos dos próprios discentes para reflexão docente, o aprendizado em cima do planejamento de aulas dos professores; [...] (Brasil, 2020).

Diante desse enredo o professor assume o papel de facilitador e aplicador de metodologias, que proporcionem ao aluno de forma concreta solucionar problemas da prática cotidiana. A metodologia ativa torna-se, nesse caso, o elemento principal do trabalho docente, reduzido ao operacional, ao saber fazer. Tem-se assim uma política de formação que nega os processos históricos e teóricos acumulados e substitui uma formação humana pautada na reflexão crítica pelo desenvolvimento de capacidades cognitivas flexíveis e competências vinculadas ao aprender a aprender e saber fazer.

A resolução pontua ainda como tarefa necessária à $\mathrm{FC}$ e como estratégia para torná-la viável o trabalho colaborativo, a formação prolongada e a coerência sistêmica. São canais que enfatizam o profissionalismo docente e a responsabilização do professor no que tange a melhoria da performance dos estudantes.

Art. $7^{\circ}[\ldots]$

III - Trabalho colaborativo entre pares - a formação é efetiva quando profissionais da mesma área de conhecimento, ou que atuem com as mesmas turmas, dialoguem e reflitam sobre aspectos da própria prática, mediados por um com maior senioridade, sendo que comunidades de prática com tutoria ou facilitação apropriada podem ser bons espaços para trabalho colaborativo, principalmente para professores de escolas menores, que não possuem colegas da mesma área de atuação para diálogo.

IV - Duração prolongada da formação - adultos aprendem melhor quando têm a oportunidade de praticar, refletir e dialogar sobre a prática, razão pela qual formações curtas não são eficazes, precisando ser contínua a interação entre os professores e os formadores, sendo, assim, a formação em serviço na escola a mais efetiva para melhoria da prática pedagógica, por proporcionar o acompanhamento e a continuidade necessários para mudanças resilientes na atuação do professor; e V - Coerência sistêmica - a formação de professores é mais efetiva quando articulada e coerente com as demais políticas das redes escolares e com as demandas formativas dos professores, os projetos pedagógicos, os currículos, os materiais de suporte pedagógico, o sistema de avaliação, o plano de carreira e a progressão salarial, sendo importante considerar sempre as evidências e pesquisas mais recentes relacionadas com a formação de professores, bem como as orientações do governo federal, de associações especializadas e as inovações do meio educacional, valendo atentar que, quando se trata da formação de 
professores, a coerência sistêmica alcança também a preparação dos formadores ou dos docentes das licenciaturas, cuja titulação se situa em nível de pósgraduação por exigência legal, uma vez que a docência nesse nível, pautada nos presentes critérios, pode propiciar, aos futuros professores, experiências de aprendizagem análogas àquela que se espera que o professor da Educação Básica propicie a seus alunos. (Brasil, 2020).

A configuração desse modelo formativo abarca, conforme o Artigo $9^{\circ}$, cinco modalidades de cursos, indicados no quadro a seguir.

\begin{tabular}{|l|l|}
\hline \multicolumn{1}{|c|}{ CURSOS } & \multicolumn{1}{|c|}{ CH } \\
\hline I - Cursos de Atualização & $\begin{array}{l}\text { carga horária mínima de 40 } \\
\text { (quarenta) horas }\end{array}$ \\
\hline II - Cursos e programas de Extensão & $\begin{array}{l}\text { com carga horária variável, } \\
\text { conforme respectivos projetos }\end{array}$ \\
\hline III - Cursos de Aperfeiçoamento & $\begin{array}{l}\text { com carga horária mínima de 180 } \\
\text { (cento e oitenta) horas }\end{array}$ \\
\hline IV - Cursos de pós-graduação lato sensu de especialização & $\begin{array}{l}\text { com carga horária mínima de 360 } \\
\text { (trezentos e sessenta) horas, de } \\
\text { acordo com as normas do CNE }\end{array}$ \\
\hline $\begin{array}{l}\text { V - Cursos ou programas de Mestrado Acadêmico ou Profissional, e } \\
\text { de Doutorado, respeitadas as normas do CNE, bem como da } \\
\text { Coordenação de Aperfeiçoamento de Pessoal de Nível Superior } \\
\text { (CAPES) }\end{array}$ \\
\hline
\end{tabular}

Fonte: Elaborado pelas autoras a partir de informações do Art. $9^{\circ}$ da Resolução n. 01/2020 (2021).

Observa-se que os cursos abrangem dois níveis de pós-graduação latu sensu e stricto sensu, como também cursos de curta atualização, aperfeiçoamento e programa de extensão. Estes devem atender os critérios estabelecidos pelo Art. $7^{\circ}$ e adequar-se às necessidades formativas das unidades e redes escolares (Parágrafo Único). Embora o Art. $7^{\circ}$ fale de "coerência e articulação sistêmica", parece não ficar claro como a formação em nível de pósgraduação será efetivada, considerando o corte de bolsas e o sucateamento da educação pública.

Entre as justificativas da aprovação desta Resolução está o atendimento a meta do atual PNE, já mencionada neste trabalho. No PNE/2024, uma das modalidades da FC deve ocorrer em nível de pós-graduação, caracterizando esta etapa como uma ação contínua incentivada pela oferta de bolsas e resultante de um regime de colaboração entre os entes federados (Estados, Distrito Federal e os Municípios). Perspectiva compartilhada pela Resolução $\mathrm{CNE} / \mathrm{CP} \mathrm{n}^{\circ}$ 2/2015, substituída pela presente resolução (n. 1/2020), que não só ignora a FC como progressão de estudos e articulada a Formação Inicial, como também rejeita a articulação entre ensino, pesquisa e extensão enquanto elementos intrínsecos de uma formação humana, crítica e democrática.

Ancoradas em estudo de Amador (2019) acerca da concepção, modelo e dimensão da FC no Brasil, é possível sugerir que embora a maioria dos cursos propostos pela presente 
Resolução aparelha-se ao modelo clássico, que conforme Amador (2019) tem sido construído a partir de "convênios firmados entre os entes municipais, estaduais e federal com as universidades para a oferta de diversos e diferentes cursos de FCP [...] aos professores [...] em exercício profissional" (Amador, 2019, p. 159). Na Resolução em tela os cursos reduzemse a especializações e aperfeiçoamento de curta ou longa duração (presencial ou a distância). A universidade no modelo clássico é vista como o lócus privilegiado para potencializar os docentes com uma formação teórica enquanto estes não dispõem do saber prático. Considerando o que propõe a Resolução quanto as caraterísticas da FC (Art. $7^{\circ}$ ), pode-se dizer que a Resolução indica uma inversão em tal modelo, isto é, a escola torna-se o lócus privilegiado e não mais a universidade, e a ênfase na teoria é substituída pela prática, pelo saber fazer.

A Resolução estabelece ainda a criação de institutos/unidades integradas como estratégia de garantir a articulação entre os cursos e programas destinados à FC e superar a fragmentação e ausência de articulação entre os diferentes saberes (Art. 10). A articulação da universidade com a escola básica constitui-se tática de grande relevância. Ambas as instituições têm papel importante na formação docente, e uma não substitui a outra. Parece que falta a compreensão de que

[...] a formação de um docente não se faz acumulando cursos, conhecimentos ou técnicas - apesar de serem acréscimos positivos -, mas sim pela reflexão do trabalho educativo e sua identidade pessoal e profissional, levando em conta as dificuldades na busca do significado interior de sua aprendizagem ou do que aprende com suas práticas (Magalhães; Azevedo, 2015, p. 31).

Em nossa leitura a Resolução, em estudo aqui, revela que está em curso um modelo formativo enredado por uma performatividade que tem por foco a eficácia escolar a partir de resultados, por isso pautado na exacerbação da prática, redução teórica e efetivação de uma pseudoautonomia. Todavia, não se trata de um engessamento total da FC ou da educação como um todo.

Pois como nos ensinou Freire (1996, p. 51):

Neutra, "indiferente" a qualquer destas hipóteses, a da reprodução da ideologia dominante ou a de sua contestação, a educação jamais foi, é, ou pode ser. É um erro decretá-la como tarefa apenas reprodutora da ideologia dominante como erro é tomá-la como uma força de desocultação da realidade, atuar livremente, sem obstáculos e duras dificuldades. Erros que implicam diretamente visões defeituosas da "História e da consciência".

E mais,

Uma política pública educacional aprovada e posta no meio escolar, como orientação a ser seguido, não significa que ela será realizada, estritamente, conforme o documento norteia, como produto a ser aplicado sem qualquer interferência. Na escola os sujeitos 
podem ressignificar a política proposta, mudando o seu curso (Saraiva; Souza, 2020, p. $66)$.

Ambos os autores permitem dizer que por mais que a FC, em pauta pelos documentos aqui analisados, caracterize-se como uma formação pragmática orientada pelo viés de uma pedagogia da competência, com a intenção de efetivar um trabalho docente a fim de melhorar os resultados das avaliações (externas e internas) e, assim, atender aos preceitos do capital neoliberal, é possível ressignificar a política de formação. Aliás, é possível transgredir e criar alternativas de enfrentamento e construção de pedagogias mais humanas e democráticas.

\section{Considerações finais}

Alinhada aos propósitos e inspirações neoliberais, a educação brasileira, desde os anos de 1990, vem sendo conduzida por uma agenda de reformas que, na prática, tem resultado na aprovação de diversos dispositivos. Estes, legalmente, prescrevem concepções, tendências e modelos de avaliação, currículo, formação, gestão, etc., voltados para atender as transformações no setor político e econômico e contribuir para manter a ordem social hegemônica sob a égide do capital internacional.

Saraiva e Souza (2020) argumentam que na América Latina e Caribe, a partir dos anos de 1980 e 1990, os Organismos Internacionais, especialmente a OCDE, intensificaram a regulação e centralidade transnacional das reformas educacionais dessas regiões em convergência da Nova Ordem Mundial, conduzida pela racionalidade neoliberal. Tomou forma nessa conjuntura um novo modelo de Gestão Pública, que pautado na reestruturação do capital tende transformar a educação em negócio lucrativo.

O neoliberalismo, de acordo com Freitas (2020), constitui-se pauta radical do capital liberal. Em sua matriz agrega o neotecnicismo e o pragmatismo enquanto princípios orientadores do desenvolvimento societal. Tais elementos têm implicações graves para a educação da classe trabalhadora, pois prevalece a ideia uma educação reduzida ao básico, ao instrumental, diretamente ligada às necessidades da cadeia produtiva. Demanda-se ainda a responsabilização dos sujeitos pelo próprio fracasso ou sucesso. A tendência dessa lógica perversa é o sucateamento e desmonte da escola e da educação pública como um bem e direito subjetivo e inalienável, conforme prescreve a Constituição Federal de 1988 e a LDB de 1996, a partir de lutas e reivindicações orquestradas pelos coletivos sociais.

No contexto da política educacional brasileira, verifica-se que os valores e ideologia do capital neoliberal manifestam-se atualmente em discursos como “educação para todos”, 'direito de aprender' [...]" (Freitas, 2020, p. 9), que interpretamos como estratégia para transformar a escola pública em produto mercadejável (Granemann, 2007) e ferramenta a serviço do mercado. Na compreensão de Frigotto (2003, p. 144), esses termos, usados pelos homens de negócio, “[...] são imposição das novas formas de sociabilidade capitalista tanto para estabelecer um novo padrão de acumulação, quanto para definir as formas concretas de integração dentro da nova reorganização da economia mundial”. 
Trata-se, na prática, de um rejuvenescimento da “[...] teoria do capital humano, com um rosto, agora, mais social" (Frigotto, 2003, p. 145), sob a gerência dos "Aparelhos privados de hegemonia burguesa" (Evangelista, 2021). Estes advogam uma "educação básica geral para formar trabalhadores com capacidade de abstração, polivalentes, flexíveis e criativos [...] subordinados à lógica do mercado, do capital e, portanto, da diferenciação, segmentação e exclusão" (Frigotto, 2003, p. 145). Lógica reverberada nos dispositivos legais como a BNCC e seu pacote anti-formação crítica. Nesta base e seus derivados, como pontuado no texto, o conceito de "competências" determina o perfil do trabalhador e consumidor que o mercado precisa, bem como de quem conduzirá tal processo, no caso, o/a professor/a. Este deve ser pragmático e comprometido com a materialidade e a operacionalização da BNCC.

Nesse aspecto, as mudanças econômica, políticas e sociais conduzidas pelo capital neoliberal impõem às políticas educacionais determinações que visam adequar o trabalhador da educação aos ditames do capital, por meio de reformas educacionais aprovadas com o intuito de materializar competências e habilidades que possibilitem a padronização, homogeneização e elitização da educação pública brasileira conforme os anseios do capital neoliberal.

Neste estudo, ficou claro para nós que o modelo de FC que preconizam a BNC-Formação Continuada, a Resolução CNE/CP n ${ }^{\circ} 1 / 2020$ e outros dispositivos apontados neste texto estão longe de atender, de fato, as necessidades e anseios dos/as professores/as brasileiros/as, pois não possuem como meta a atualização e complementação ao longo da carreira e muitos menos consideram a formação inicial e o contexto no qual atuam os/as docentes da educação básica ao ensino superior.

A formação continuada oferecida e indicada pelos dispositivos legais e órgãos governamentais ou sistemas privados tem a "[...] perspectiva mercadológica, enaltecendo modelos, na medida em que pressupõe o professor como executor, responsável pelo preparo de alunos para o mercado de trabalho, na perspectiva do novo desenvolvimentismo" (Magalhães; Azevedo, 2015).

Vê-se, portanto, surgir dos porões obscuros do velho tecnicismo, mas agora muito bem arrumada e com uma nova roupagem, um "novo modelo de formação continuada", mas sem deixar de lado suas competências e habilidades que destituem, cada vez mais, a "[...] autonomia que lhes permita refletir, criar, inovar o processo de ensino-aprendizagem junto a seus alunos e a partir de contextos próprios" (Magalhães; Azevedo, 2015).

Conclui-se, assim, que a formação continuada é pautada pela Resolução CNE/CP ${ }^{\circ}$ 1/2020 como estratégia dos preceitos e interesses neoliberais sob a liderança dos "Aparelhos privados de hegemonia burguesa" (Evangelista, 2021), com a intencionalidade de preparar trabalhadores aptos a potencializar a cadeia produtiva. Como tratado no texto, tal perspectiva terá implicações nocivas para o trabalho docente e para o processo formativo do aluno da Educação Básica. 


\section{Referências}

ALBINO, Ângela Cristina Alves; SILVA, Andréia Ferreira da. BNCC e BNC da formação de professores: repensando a formação por competências. Revista Retratos da Escola, Brasília, v. 13, n. 25, p. 137-153, jan./maio 2019. Disponível em: http://retratosdaescola.emnuvens.com.br/rde/article/view/966. Acesso em: 27 abr. 2021.

AMADOR, Judenilson Teixeira. Concepções e modelos de formação continuada de professores: um estudo téorico. Revista Humanidades \& Inovação, v. 6, n. 2, p. 150-167, 2019. Disponível em: https://revista.unitins.br/index.php/humanidadeseinovacao/article/view/862. Acesso em: 10 ago. 2021.

ASSOCIAÇÃO NACIONAL DE PÓS-GRADUAÇÃO E PESQUISA EM EDUCAÇÃO - ANPED. Uma formação formatada. $2019 . \quad$ Disponível em: https://www.anped.org.br/sites/default/files/images/posicao_da_anped_sobre_o_texto_referencia_diretrize s_curriculares_nacionais_e_base_nacional_comum_para_a_formacao_inicial_e_continuada_de_professor es_da_educ.pdf. Acesso em: 10 maio 2021.

BARRETTO, Elba Siqueira de Sá. Trabalho docente e modelos de formação: velhos e novos embates e representações. Cadernos de Pesquisa, v. 40, n. 140, p. 427-443, maio/ago. 2010. Disponível em: https://www.scielo.br/j/cp/a/H7dM3LbqDq4cwfZQ5vyLbdj/?format=pdf\&lang=pt. Acesso em: 12 ago. 2021.

BRASIL. Lei n ${ }^{\circ}$ 9.394, de 20 de dezembro de 1996. Estabelece as Diretrizes e Bases da Educação Nacional. Diário Oficial da União, Brasília-DF, 23 dez. 1996. Disponível em: http://www.planalto.gov.br/ccivil_03/leis/19394.htm. Acesso em: 10 ago. 2021.

BRASIL. Ministério da Educação. Resolução CNE/CP n ${ }^{\circ}$ 1, de 27 de outubro de 2020. Dispõe sobre as Diretrizes Curriculares Nacionais para a Formação Continuada de Professores da Educação Básica e institui a Base Nacional Comum para a Formação Continuada de Professores da Educação Básica (BNC-Formação Continuada). In: Diário Oficial da União, Brasília-DF, Seção 1, p. 103-106, 29 out. 2020. Disponível em: http://portal.mec.gov.br/docman/outubro-2020-pdf/164841-rcp001-20/file. Acesso em: 02 ago.2021.

BRASIL. Ministério da Educação. Conselho Nacional de Educação/Conselho Pleno (CNE/CP). Resolução $\mathrm{CNE} / \mathrm{CP} \mathrm{n}^{\circ} 2$, de $1^{\circ}$ de julho de 2015. Define as Diretrizes Curriculares Nacionais para a formação inicial em nível superior (cursos de licenciatura, cursos de formação pedagógica para graduados e cursos de segunda licenciatura) e para a formação continuada. Diário Oficial da União, Brasília-DF, Seção 1, n. 124, p. 8-12, 2 jul. 2015.

BRASIL. Ministério da Educação. Conselho Nacional de Educação. Resolução CNE/CP $n^{\circ}$ 2, de 22 de dezembro de 2017. Institui e orienta a implantação da Base Nacional Comum Curricular, a ser respeitada obrigatoriamente ao longo das etapas e respectivas modalidades no âmbito da Educação Básica. Diário Oficial da União, Brasília-DF, Seção 1, p. 41-44, 22 dez. 2017. Disponível em: http://basenacionalcomum.mec.gov.br/images/historico/RESOLUCAOCNE_CP222DEDEZEMBRODE2 017.pdf. Acesso em: 10 ago. 2021.

BRASIL. Ministério da Educação. Conselho Nacional de Educação. Resolução CNE/CP n ${ }^{\circ}$ 04, 18 de dezembro de 2018. Institui a Base Nacional Comum Curricular na Etapa do Ensino Médio (BNCC-EM), como etapa final da Educação Básica, nos termos do artigo 35 da LDB, completando o conjunto constituído pela BNCC da Educação Infantil e do Ensino Fundamental, com base na Resolução CNE/CP n ${ }^{\circ}$ 2/2017, fundamentada no Parecer CNE/CP nº 15/2017. Diário Oficial da União, Brasília-DF, Seção 1, p. 120-122, 18 dez. 2018. Disponível em: http://portal.mec.gov.br/docman/dezembro-2018-pdf/104101-rcp004-18/file. Acesso em: 10 ago. 2021.

BRASIL. Lei $\mathbf{n}^{\mathbf{0}}$ 12.056, de 13 de outubro de 2009. Acrescenta parágrafos ao art. 62 da Lei $\mathrm{n}^{\circ} 9.394$, de 20 de dezembro de 1996, que estabelece as diretrizes e bases da educação nacional. Disponível em: http://www.planalto.gov.br/ccivil_03/_ato2007-2010/2009/lei/112056.htm. Acesso em: 10 ago. 2021. 
BRASIL. Decreto $\mathbf{n}^{\mathbf{0}}$ 8.752, de 9 de maio de 2016. Dispõe sobre a Política Nacional de Formação dos Profissionais da Educação Básica. Disponível em: http://www.planalto.gov.br/ccivil_03/_ato20152018/2016/decreto/d8752.htm. Acesso em 20 jul. 2021.

BRASIL. Lei no 13.005, de 25 de junho de 2014. Aprova o Plano Nacional de Educação - PNE e dá outras providências. Diário Oficial da União, Brasília-DF, 26 jun. 2014. Disponível em: http://www.planalto.gov.br/ccivil_03/_ato2011-2014/2014/lei/113005.htm. Acesso em: 12 ago. 2021.

CURADO SILVA, Kátia Augusta Curado Pinheiro Cordeiro. A (de)Formação de Professores na Base Nacional Comum Curricular. In: UCHOA, Antônio Marcos da; LIMA, Átila de Menezes; SENA, Ivânia Paula Freitas de Souza (Org.). Diálogos Críticos, volume 2: reformas educacionais: avanço ou precarização da educação pública? [recurso eletrônico]. Porto Alegre: Editora Fi, 2020. p. 102-122.

CURADO SILVA, Kátia Augusta Curado Pinheiro Cordeiro. Epistemologia da práxis na formação de professores: perspectiva crítico emancipadora. Revista de Ciências Humanas, Frederico Westphalen, v. 31, n. 2, p. 121-135, 2017. Disponível em: http://revistas.fw.uri.br/index.php/revistadech/article/view/2468. Acesso em: 12 jul. 2021.

EVANGELISTA, Olinda. De protagonistas a obstáculos: aparelhos privados de hegemonia e conformação docente no Brasil, 2021. Não Publicado.

FREIRE, Paulo. Pedagogia da Autonomia: saberes necessários à prática educativa. São Paulo: Paz e Terra, 1996.

FREITAS, Luiz Carlos de. Os reformadores empresariais da educação: da desmoralização do magistério à destruição do sistema público de educação. Educ. Soc., Campinas-SP, v. 33, n. 119, p. 379-404, abr./jun. 2012. https://www.scielo.br/j/es/a/PMP4Lw4BRRX4k8q9W7xKxVy/?format=pdf\&lang=pt. Acesso em: 28 jul. 2021.

FREITAS, Luiz Carlos de. Os reformadores empresariais da educação e a disputa pelo controle do processo pedagógico na escola. Educ. Soc., Campinas-SP, v. 35, n. 129, p. 1085-1114, out./dez. 2014. Disponível em: https://www.scielo.br/j/es/a/xm7bSyCfyKm64zWGNbdy4Gx/?lang=pt\&format=pdf. Acesso: 28 jul. 2021.

FREITAS, Luiz Carlos de. Prefácio. In: UCHOA, Antônio Marcos da Conceição; LIMA, Átila de Menezes; SENA, Ivânia Paula Freitas de Sousa (Org.). Diálogos Críticos, volume 2: reformas educacionais: avanço ou precarização da educação pública? [recurso eletrônico]. Porto Alegre: Editora Fi, 2020. p. 9-10.

FRIGOTTO, Gaudêncio. Educação e a crise do capitalismo real. 5. ed. São Paulo: Cortez, 2003.

GRANEMANN, Sara. Políticas sociais e finaceirização dos direitos do trabalho. Em Pauta, Rio de Janeiro, n. 20, p. 86-94, jan. 2007.

HÖFLING, Eloisa de Mattos. Estado e políticas (públicas) sociais. Cadernos Cedes, ano XXI, n. 55, nov. 2001. Disponível em: http://www.scielo.br/pdf/ccedes/v21n55/5539.pdf. Acesso em: 15 dez. 2019.

HYPOLITO, Álvaro Moreira. Padronização curricular, padronização da formação docente: desafios da formação pós-BNCC. Revista Práxis Educacional, v. 17, n. 46, p. 1-18, jul./set. |2021. Disponível em: https://periodicos2.uesb.br/index.php/praxis/article/view/8915. Acesso em: 20 jul. 2021.

JINKINGS, Ivana. Apresentação. In: MÉSZÁROS, István. A educação para além do capital. São Paulo: Boitempo, 2005.

MAGALHÃES, Lígia Karan Corrêa de; AZEVEDO, Leny Cristina Soares Souza. Formação continuada e suas implicações: entre a lei e o trabalho docente. Cadernos Cedes, Campinas, v. 35, n. 95, p. 15-36, jan./abr. 2015. 2021.

PEREIRA, Jennifer Nascimento; EVANGELISTA, Olinda. Quando o capital educa o educador: BNCC, nova 
escola e Lemann. Movimento-Revista de Educação, Niterói, ano 6, n.10, p. 65-90, jan./jun. 2019. Disponível em: https://periodicos.uff.br/revistamovimento/article/view/32664. Acesso em: 02 ago. 2021

SARAIVA, Ana Maria Alves; SOUZA Juliana de Fátima. A formação docente e as organizações internacionais: uma agenda focada na performatividade dos professores e na eficácia escolar. Currículo sem Fronteiras, v. 20, n. $1, \quad$ p. 129-147, jan./abr. 2020. Disponível em: https://www.curriculosemfronteiras.org/vol20iss1articles/saraiva-souza.html. Acesso em: 30 jul. 2021.

SOARES, Sebastião Silva. Novos cenários e velhos debates no campo da política de formação de professores no Brasil. Momento: Diálgos em Educação, v. 27, n. 2, p. 57-75, maio/ago. 2018. Disponível em: https://periodicos.furg.br/momento/article/view/8045. Acesso em: 28 jul. 2021.

TARDIF, Muarice. Saberes docentes e formação profissional. Petrópolis, RJ: Vozes, 2002.

\section{Correspondência}

Eliane Miranda Costa: Professora na Faculdade de Educação e Ciências Humanas do Campus Universitário do Marajó Breves (CUMB), Universidade Federal do Pará (UFPA), Graduada em Pedagogia (UFPA), mestre em Educação (UEPA) e doutora em Antropologia (UFPA).

E-mail: elianec@ufpa.br

Cleide Carvalho de Matos: Professora na Faculdade de Educação e Ciências Humanas do Campus Universitário do Marajó Breves (CUMB), Universidade Federal do Pará (UFPA), Graduada em Pedagogia (UFPA), mestre e doutora em Educação (UFPA).

E-mail: cleidematos@ufpa.br

Vivianne Nunes da Silva Caetano: Professora na Faculdade de Educação e Ciências Humanas do Campus Universitário do Marajó Breves (CUMB), Universidade Federal do Pará (UFPA), Graduada em Pedagogia (UFPA), mestre em Educação (UEPA) e doutora em Antropologia (UFPA)..

E-mail: vns@ufpa.br

Texto publicado em Currículo sem Fronteiras com autorização dos autores. 